\title{
Molecular pathological diagnosis for early esophageal cancer in Kazakh patients
}

\author{
IDIRIS AWUT ${ }^{1}$, MADINIYET NIYAZ $^{2}$, HADETI BIEKEMITOUFU ${ }^{3}$, \\ ZHU ZHANG ${ }^{1}$, ILYAR SHEYHEDIN ${ }^{1}$ and WEN HAO ${ }^{2}$ \\ ${ }^{1}$ Department of Thoracic Surgery; ${ }^{2}$ Xinjiang Esophageal Cancer Research Institute, Center of Medical Research; \\ ${ }^{3}$ Department of Pathology, First Affiliated Hospital of Xinjiang Medical University, Urumqi, Xinjiang 830054, P.R. China
}

Received September 8, 2011; Accepted November 25, 2011

DOI: $10.3892 / \mathrm{ol} .2011 .547$

\begin{abstract}
Chromosome abnormalities in cancer cells occur early in carcinogenesis. We employed DNA probes for the detection of cancer cells in surgical specimens in Kazakh patients with suspected esophageal carcinoma, to analyze the application of this technique during the early diagnosis of esophageal cancer. Comparative analysis was used to compare the results of pathological diagnosis with the results of FISH. We performed esophagofiberscopic biopsy examinations in 50 Kazakh patients with suspected esophageal carcinoma, including 40 males and 10 females, with an average age of 56.8 years. The final diagnosis was esophageal squamous cell carcinoma in 47 patients, and adenocarcinoma, mucinous carcinoma and small cell carcinoma in one patient each. The pathological findings of the biopsy were positive in 45 cases, and false-negative in 5 . The sensitivity and specificity of pathological diagnosis were 87.2 and $100 \%$, respectively. Using FISH to examine the same tissues, we found that 48 cases showed aberrant copy numbers in either chromosome 3 or 17 , and 2 cases were false-negative, with a sensitivity and specificity of 94.8 and $100 \%$, respectively. The copy numbers of centromeres in chromosome 3 were significantly higher than the copy numbers of centromeres in chromosome $17(\mathrm{P}=0.0001)$. Compared with biopsy pathology, the FISH test was more sensitive. Being an objective and qualitative method, the technology of molecular pathological diagnosis may effectively increase the early diagnostic rate of esophageal cancer. In addition, the centromere probe in chromosome 3 may be the most sensitive probe for the diagnosis of esophageal cancer in Kazakh patients.
\end{abstract}

Correspondence to: Professor Wen Hao, First Affiliated Hospital of Xinjiang Medical University, 137 Liyushan South Road, Urumqi, Xinjiang 830054, P.R. China

E-mail:dr.wenhao@163.com

Abbreviations: FISH, fluorescence in situ hybridization; EC, esophageal cancer; SSC, standard saline citrate

Key words: aneuploidy, fluorescence in situ hybridization, molecular pathology, esophageal cancer, Kazakh patients

\section{Introduction}

The incidence of esophageal cancer (EC) has been high $(68.88 / 100,000)$ among the Kazakh people living in the Xinjiang Uygur Autonomous Region (Northwest of China) during the past 30 years. Nevertheless, early detection and treatment rates of EC remain low, and it consequently has a poor prognosis. If early diagnosis and treatment were possible, the 5-year survival rate could be increased to above $90 \%$ as in other countries/regions that have early detection programs (1-3).

Conventional pathological diagnosis plays a crucial role in the diagnosis of EC, and provides important information on tumor differentiation and the degree of morphological changes $(4,5)$. However, due to the limitations of biopsy pathology, discrepancies between pathological diagnosis and actual diagnosis occasionally occur, making clinical diagnosis and treatment difficult. There is, therefore, a need to find a more objective and quantitative method to distinguish benign from malignant cells.

A number of studies suggest that the incidence and evolution of EC involves a variety of chromosomal anomalies. During carcinogenesis, a cell goes through molecular cytogenetic changes prior to showing morphological changes. Nuclear chromosome abnormality, which can be observed in cancer cells, is an early event during the process of tumorigenesis, and it has become the determining objective index of cancer cells.

Cell nuclear aneuploidy is one of the most common features of a number of types of cancer, including EC (6,7). Malignant cells are therefore capable of being diagnosed by detecting aneuploidy, usually found in aneusomic nuclei. Fluorescence in situ hybridization (FISH) technology is a rapid and sensitive method for detecting aneusomy of a specific chromosome and is widely used in the diagnosis of hematological malignancies, lung, breast and kidney cancer, with high sensitivity and specificity (8-11). The advantage of the FISH method has been considered to lie in its objective and quantitative evaluation of malignant cells.

Some studies have suggested that FISH has a certain value in detecting a variety of cancer cells in conventional cytology and early cancer diagnosis (12-14). However, no comparative study on conventional pathology with FISH using biopsy tissues for cancer cell detection has been reported previously. 
In this study, 50 Kazakh patients with suspected EC underwent FISH examination and conventional pathological diagnosis using biopsied samples, to analyze the value of the clinical applications and prospective uses of the FISH method in the early diagnosis of EC.

\section{Patients and methods}

Patients. This study was approved by the Ethics Committee of the First Affiliated Hospital of Xinjiang Medical University, China. Between March 2009 and December 2010, 50 Kazakh EC patients were admitted to the Department of Thoracic Surgery (First Affiliated Hospital of Xinjiang Medical University) and underwent resection. The patients included 40 males and 10 females, with an average age of 56.8 years (range 31-82).

Final pathological diagnosis confirmed esophageal squamous cell carcinoma in 47 cases post-operatively, including well differentiated tumors in 23 cases, moderately differentiated tumors in 18 cases, and poorly differentiated tumors in 6 cases; as well as poorly differentiated adenocarcinoma in 1 case, mucinous adenocarcinoma in 1 case, and small cell carcinoma in 1 case (Table I).

Methods. To determine the diagnosis pre-operatively, all patients underwent esophagofiberscopic examination, and sites that appeared to be suspicious for malignancy were biopsied using standard biopsy forceps. After performing touch preparations of cells on glass slides with the specimen, the same specimens were used for conventional pathological diagnosis. Informed consent was obtained from all 50 patients.

Samples were stained with hematoxylin and eosin (H\&E). Pathological evaluations were performed by three qualified pathologists from the Department of Pathology.

Pathomorphological classification of biopsy specimens were as follows: class I was mild grade squamous epithelial hyperplasia; class II was mild dysplasia; class III was moderate dysplasia, but without any malignant characteristics; class IV was severe dysplasia, i.e., carcinoma in situ; class $\mathrm{V}$ was typical cancer tissue. Classes IV and V were considered to be EC.

Touch preparations of cells were made on glass slides and air dried overnight at room temperature and then stored at $-80^{\circ} \mathrm{C}$. Centromeric probes labeled with fluorochrome were used for the visualization and enumeration of copy numbers. Spectrum orange and green labeled probes were used to visualize centromeric regions of chromosomes 3 and 17. Reagents were purchased from Abbott Molecular, Inc. (Des Plaines, IL, USA).

Preparation of slides. Cells were denatured with $70 \%$ formamide and then washed twice in standard saline citrate (SSC) at $74^{\circ} \mathrm{C}$ and at room temperature, respectively, for $2 \mathrm{~min}$ in a water bath. Then, slides were dehydrated through a graded ethanol series (70, 85 and $100 \%$, each for $2 \mathrm{~min}$ ). We then applied $10 \mu \mathrm{l}$ of hybridization solution containing $1 \mu \mathrm{l}$ of each of the DNA probes, $7 \mu 1$ of hybridization buffer and $1 \mu \mathrm{l}$ of double distilled water. This was covered with a cover slip and sealed with rubber cement. Following incubation for $16 \mathrm{~h}$ at $42^{\circ} \mathrm{C}$ in a humidity-controlled chamber, the slides were washed with an SSC solution for $5 \mathrm{~min}$ at $74^{\circ} \mathrm{C}$, and at room
Table I. Patient charateristics.

\begin{tabular}{|c|c|c|c|}
\hline Case & Gender & Age & Diagnosis \\
\hline 1 & M & 55 & $\mathrm{Sq}$ \\
\hline 2 & $\mathrm{~F}$ & 63 & $\mathrm{Sq}$ \\
\hline 3 & M & 50 & $\mathrm{Sq}$ \\
\hline 4 & M & 48 & $\mathrm{Sq}$ \\
\hline 5 & $\mathrm{~F}$ & 65 & $\mathrm{Sq}$ \\
\hline 6 & M & 56 & $\mathrm{Sq}$ \\
\hline 7 & $\mathrm{~F}$ & 52 & $\mathrm{Sq}$ \\
\hline 8 & M & 63 & $\mathrm{Sq}$ \\
\hline 9 & M & 66 & Scc \\
\hline 10 & $\mathrm{~F}$ & 59 & $\mathrm{Sq}$ \\
\hline 11 & M & 54 & $\mathrm{Sq}$ \\
\hline 12 & M & 47 & $\mathrm{Sq}$ \\
\hline 13 & M & 63 & $\mathrm{Sq}$ \\
\hline 14 & M & 82 & $\mathrm{Sq}$ \\
\hline 15 & $\mathrm{~F}$ & 59 & $\mathrm{Sq}$ \\
\hline 16 & M & 31 & $\mathrm{Sq}$ \\
\hline 17 & M & 51 & $\mathrm{Sq}$ \\
\hline 18 & M & 50 & $\mathrm{Sq}$ \\
\hline 19 & M & 64 & $\mathrm{Sq}$ \\
\hline 20 & M & 46 & $\mathrm{Sq}$ \\
\hline 21 & M & 44 & $\mathrm{Sq}$ \\
\hline 22 & M & 56 & $\mathrm{Sq}$ \\
\hline 23 & M & 42 & M-ad \\
\hline 24 & M & 61 & $\mathrm{Sq}$ \\
\hline 25 & $\mathrm{~F}$ & 48 & $\mathrm{Sq}$ \\
\hline 26 & M & 42 & $\mathrm{Sq}$ \\
\hline 27 & M & 39 & $\mathrm{Sq}$ \\
\hline 28 & M & 71 & $\mathrm{Sq}$ \\
\hline 29 & $\mathrm{~F}$ & 60 & $\mathrm{Sq}$ \\
\hline 30 & M & 56 & $\mathrm{Sq}$ \\
\hline 31 & M & 45 & $\mathrm{Sq}$ \\
\hline 32 & M & 64 & $\mathrm{Sq}$ \\
\hline 33 & M & 72 & $\mathrm{Sq}$ \\
\hline 34 & M & 65 & $\mathrm{Sq}$ \\
\hline 35 & M & 67 & $\mathrm{Sq}$ \\
\hline 36 & M & 65 & $\mathrm{Sq}$ \\
\hline 37 & M & 58 & $\mathrm{Sq}$ \\
\hline 38 & $\mathrm{~F}$ & 54 & $\mathrm{Sq}$ \\
\hline 39 & M & 50 & $\mathrm{Sq}$ \\
\hline 40 & $\mathrm{~F}$ & 56 & $\mathrm{Sq}$ \\
\hline 41 & M & 65 & $\mathrm{Sq}$ \\
\hline 42 & $\mathrm{M}$ & 56 & $\mathrm{Sq}$ \\
\hline 43 & $\mathrm{M}$ & 63 & $\mathrm{Sq}$ \\
\hline 44 & $\mathrm{M}$ & 69 & $\mathrm{Sq}$ \\
\hline 45 & $\mathrm{M}$ & 71 & $\mathrm{Sq}$ \\
\hline 46 & $\mathrm{M}$ & 65 & $\mathrm{Sq}$ \\
\hline 47 & $\mathrm{M}$ & 62 & $\mathrm{Sq}$ \\
\hline 48 & $\mathrm{M}$ & 56 & $\mathrm{Sq}$ \\
\hline 49 & $\mathrm{~F}$ & 37 & $\mathrm{Sq}$ \\
\hline 50 & $\mathrm{M}$ & 56 & $\mathrm{Ad}$ \\
\hline
\end{tabular}

M, male; F, female; Sq, squamous cell carcinoma; Ad, adenocarcinoma; Scc, small cell carcinoma; M-ad, mucinous adenocarcinoma.

temperature for $2 \mathrm{~min}$. Diamidinophenylindole (DAPI, II) $(5 \mu \mathrm{l})$ was applied to each spot and covered with a cover slip. The slides were observed under a fluorescence microscope that was connected to a cooled charge-coupled device camera 

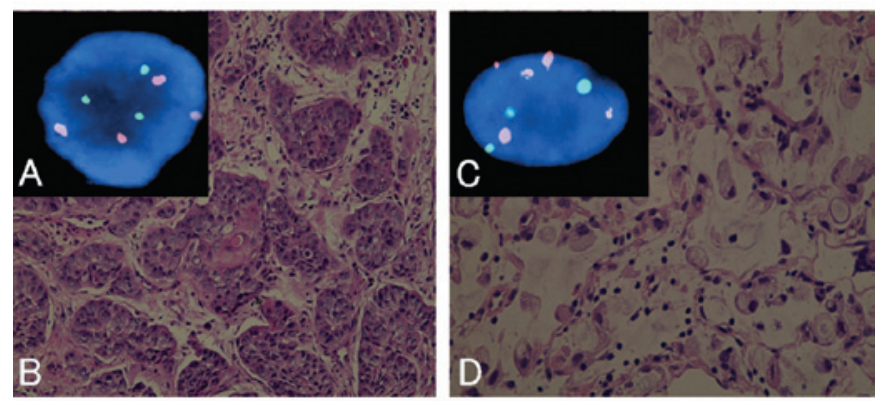

Figure 1. FISH analysis of the centromere of chromosome 3 (orange signals) and chromosome 17 (green signals). The normal representative is nuclei carrying 2 copies of the centromere of chromosomes 3 and 17. (A and B) The pathology is viewed by $\mathrm{H} \& \mathrm{E}$ staining; magnification $\mathrm{x} 400$. The results revealed squamous cell carcinoma (case 17) of grade V. FISH representative nuclei carry 4 copies of the centromere of chromosome 3 , and 3 copies of the centromere of chromosome 17. (C and D) The pathology is viewed by $\mathrm{H} \& \mathrm{E}$ staining; magnification, $\mathrm{x} 400$. The results revealed adenocarcinoma (case 50) of grade V. FISH representative nuclei carry 5 copies of the centromere of chromosome 3 and 3 copies of the centromere of chromosome 17. $\mathrm{H} \& \mathrm{E}$, hematoxylin and eosin; FISH, fluorescence in situ hybridization.

and an image analyzer system (Leica Microsystems, Ltd., Germany).

FISH analysis. FISH signal analysis was performed as follows: all cells, with the exception of damaged cells or those with overlapping nuclei, were evaluated. We counted 100 nuclei from each patient, and the total number of centromeric signals was recorded. When the percentage of hyperdisomic nuclei with more than three copies for at least one nucleus was $>10 \%$, we diagnosed malignancy.

FISH diagnosis was made without knowing the result of the conventional pathological diagnosis. Similarly, the results of FISH analysis were not shown to the pathologists. Thus, the two diagnoses were independently performed in a blind manner.

Statistical analysis. An IBM SPSS 16.0 statistical software package (IBM Corporation, NY, USA) was used for statistical analysis. The student's paired t-test was used to test the difference between the number of countable centromere signals of chromosome 3 and 17 . $\mathrm{P}<0.05$ was considered to indicate a statistically significant difference.

\section{Results}

Patients and FISH analysis. Biopsy pathology yielded a diagnosis of primary EC in 45 patients, including squamous cell carcinoma in 42 cases, adenocarcinoma in 1 case, mucinous adenocarcinoma in 1 case, and small cell carcinoma in 1 case.

We classify the cases as follows: 3 cases were classified as class II; 2 cases as class III; 4 cases as class IV; 41 cases as class V. Five cases were false-negative but there were no false-positive cases. The sensitivity and specificity were 87.2 and $100 \%$, respectively.

FISH analysis revealed that 48 cases had abnormal copy numbers in either chromosome 3 or 17. Representative findings of the pathology and FISH are shown in Fig. 1.

The FISH method yielded 2 false-negative and no false-positive cases, with a sensitivity and specificity of 94.8 and $100 \%$, respectively (Table II). The copy numbers of centromeres in chromosome 3 were significantly higher $(\mathrm{P}=0.0001)$ than the centromeres of chromosome 17.

\section{Discussion}

The Xinjiang Uygur Autonomous Region is a multi-ethnic area located in the Northwest of China and the Kazakh ethnic group has a high incidence of EC. Improved early diagnosis of EC among this ethnic group is likely to lessen the burden of EC (1).

Aneuploidy is present in the nuclei of cancer cells. It is a common molecular pathological characteristic in human carcinoma $(7,15,16)$. A number of studies have suggested that using DNA probes for the detection of aneuploidy in cancer cells may be a superior technique to conventional pathological diagnosis (8-12,14). Han et al examined 113 EC patients using specific centromere DNA probes 3, 8, 10, 12, 17 and 20, and found that chromosomal signal numbers and all chromosomes were found to have abnormal copy numbers (12). In their study, Fritcher et al analyzed esophageal adenocarcinoma using the FISH method with the centromeric region probes C-MYC, P16, HER 2 and 20q13 (9). These authors found that the sensitivity of cytology is only $45 \%$ for the detection of esophageal adenocarcinoma, but FISH yielded a detection rate of $100 \%$. The same study used FISH analysis with centromeric probes 7, 11, 12,17 and 18. Aneusomy was not found in the normal controls of any chromosomes. By contrast, chromosomal abnormalities were found in all carcinoma specimens (13).

Using FISH technology, the genetic analysis of interphase nuclei closely reflected the real changes in chromosomes. Simultaneous use of two or more different fluorescent-labeled probes resulted in high sensitivity and specificity for the detection of esophageal, lung and breast cancer cells $(9,11,14)$. Therefore, we performed FISH analysis and conventional pathological diagnosis for biopsied specimens in suspected EC patients to compare their sensitivity and specificity in order to analyze whether the early diagnosis of EC is possible or not and to obtain its clinical value. Our results showed that using the molecular pathological diagnostic method during the process of EC diagnosis is more accurate than conventional pathological diagnosis. This is consistent with the results of similar studies $(8,12,14,17)$.

In our study, we selected the centromeres in chromosome 3 and 17 probes, and set the cut-off value of the percentage of hyperdisomic cells at $10 \%$, whereas normal cells often have less than $6 \%$. This discrepancy is probably due to counting sister chromatids as copies.

The sensitivity and specificity by biopsy pathology were 87.2 and $100 \%$, respectively. Using FISH analysis, the sensitivity and specificity were 94.8 and $100 \%$, respectively. These results indicated that FISH is more sensitive than biopsy pathology, the latter yielding 5 false-negative results: class II in 3 cases, class III in 2 cases. Post-operative final pathological diagnoses in all of these patients were esophageal squamous cell carcinomas. FISH yielded 2 false-negative results, both of which matched the 2 pathologically false-negative class II cases. This finding was probably due to the shallowness of the biopsies.

FISH successfully detected cancer cells in 3 cases in which biopsy pathology was false-negative. Post-operative 
Table II. Results of FISH, biopsy pathology and final pathology.

\begin{tabular}{|c|c|c|c|c|c|c|c|}
\hline Case & $\begin{array}{c}3 \text { copies } \\
\text { CEP3/CEP17 }\end{array}$ & $\begin{array}{c}4 \text { copies } \\
\text { CEP3/CEP17 }\end{array}$ & $\begin{array}{c}\geq 5 \text { copies } \\
\text { CEP3/CEP17 }\end{array}$ & $\begin{array}{l}\text { Hyperdisomy } \\
(\%)\end{array}$ & $\begin{array}{c}\text { Biopsy } \\
\text { pathology }\end{array}$ & FISH & Pathology \\
\hline
\end{tabular}

\begin{tabular}{|c|c|c|c|c|c|c|c|}
\hline 1 & $12 / 9$ & $23 / 18$ & $11 / 12$ & $46 / 39$ & $\mathrm{Sq}, \mathrm{V}$ & Positive & pT2N2M0 \\
\hline 2 & $18 / 17$ & $17 / 13$ & $23 / 23$ & $58 / 53$ & $\mathrm{Sq}, \mathrm{V}$ & Positive & pT2NOM0 \\
\hline 3 & $26 / 18$ & $23 / 20$ & $19 / 21$ & $68 / 59$ & $\mathrm{Sq}, \mathrm{V}$ & Positive & pT4N3M0 \\
\hline 4 & $14 / 15$ & $19 / 15$ & $18 / 16$ & $51 / 46$ & $\mathrm{Sq}, \mathrm{V}$ & Positive & pT2NOM0 \\
\hline 5 & $23 / 16$ & $20 / 21$ & $16 / 16$ & $59 / 53$ & $\mathrm{Sq}, \mathrm{IV}$ & Positive & pT3N1M0 \\
\hline 6 & $27 / 23$ & $20 / 17$ & $27 / 26$ & $74 / 66$ & $\mathrm{Sq}, \mathrm{V}$ & Positive & pT2N1M0 \\
\hline 7 & $15 / 17$ & $25 / 19$ & $25 / 20$ & $65 / 56$ & $\mathrm{Sq}, \mathrm{V}$ & Positive & pT2N1M0 \\
\hline 8 & $11 / 8$ & $11 / 16$ & $19 / 20$ & $41 / 44$ & $\mathrm{Sq}, \mathrm{V}$ & Positive & pT3N2M0 \\
\hline 9 & $31 / 28$ & $25 / 20$ & $33 / 32$ & $89 / 80$ & Scc, V & Positive & pT2N1M0 \\
\hline 10 & $25 / 26$ & $30 / 25$ & $18 / 18$ & $73 / 69$ & $\mathrm{Sq}, \mathrm{V}$ & Positive & pT3N1M0 \\
\hline 11 & $22 / 20$ & $27 / 28$ & $20 / 23$ & $69 / 71$ & $\mathrm{Sq}, \mathrm{V}$ & Positive & pT2N0M0 \\
\hline 12 & $33 / 29$ & $30 / 31$ & $19 / 12$ & $85 / 72$ & $\mathrm{Sq}, \mathrm{V}$ & Positive & pT4N1M0 \\
\hline 13 & $3 / 1$ & $1 / 2$ & $1 / 0$ & $5 / 3$ & ${ }^{a}$ Negative, II & ${ }^{a}$ Negative & pT1N0M0 \\
\hline 14 & $35 / 27$ & $29 / 26$ & $31 / 29$ & $95 / 82$ & $\mathrm{Sq}, \mathrm{V}$ & Positive & pT3N2M0 \\
\hline 15 & $19 / 13$ & $22 / 25$ & $22 / 19$ & $63 / 57$ & $\mathrm{Sq}, \mathrm{V}$ & Positive & pT2NOMO \\
\hline 16 & $19 / 15$ & $22 / 22$ & $17 / 18$ & $58 / 55$ & $\mathrm{Sq}, \mathrm{V}$ & Positive & pT3N1M0 \\
\hline 17 & $24 / 20$ & $30 / 26$ & $14 / 17$ & $68 / 63$ & $\mathrm{Sq}, \mathrm{V}$ & Positive & pT2N1M0 \\
\hline 18 & $12 / 9$ & $11 / 14$ & $21 / 15$ & $44 / 38$ & $\mathrm{Sq}, \mathrm{V}$ & Positive & pT3N1M0 \\
\hline 19 & $23 / 17$ & $23 / 20$ & $21 / 21$ & $67 / 58$ & $\mathrm{Sq}, \mathrm{V}$ & Positive & pT3NOM0 \\
\hline 20 & 9/11 & $12 / 12$ & $9 / 7$ & $40 / 30$ & $\mathrm{Sq}, \mathrm{IV}$ & Positive & pT2N1M0 \\
\hline 21 & $26 / 21$ & $12 / 9$ & $17 / 15$ & $55 / 45$ & $\mathrm{Sq}, \mathrm{V}$ & Positive & pT3N2M0 \\
\hline 22 & $17 / 14$ & $29 / 23$ & $19 / 11$ & $65 / 48$ & $\mathrm{Sq}, \mathrm{V}$ & Positive & pT3NOM0 \\
\hline 23 & $22 / 16$ & $28 / 19$ & $17 / 20$ & $67 / 55$ & M-ad,V & Positive & pT4N2M0 \\
\hline 24 & $29 / 16$ & $25 / 25$ & $17 / 18$ & $71 / 59$ & $\mathrm{Sq}, \mathrm{V}$ & Positive & pT2NOM0 \\
\hline 25 & $2 / 2$ & $0 / 2$ & $1 / 0$ & $3 / 4$ & ${ }^{a}$ Negative, II & ${ }^{\mathrm{a}}$ Negative & pT2NOMO \\
\hline 26 & $13 / 15$ & $7 / 9$ & $8 / 8$ & $28 / 32$ & $\mathrm{Sq}, \mathrm{V}$ & Positive & pT3N1M0 \\
\hline 27 & $17 / 15$ & $10 / 15$ & $5 / 5$ & $32 / 35$ & $\mathrm{Sq}, \mathrm{V}$ & Positive & pT3NOM0 \\
\hline 28 & $58 / 52$ & $12 / 12$ & $15 / 13$ & $85 / 77$ & $\mathrm{Sq}, \mathrm{V}$ & Positive & pT3N1M0 \\
\hline 29 & $30 / 24$ & $22 / 16$ & $20 / 21$ & $72 / 61$ & $\mathrm{Sq}, \mathrm{V}$ & Positive & pT3N1M0 \\
\hline 30 & $55 / 47$ & $21 / 19$ & $9 / 9$ & $85 / 75$ & $\mathrm{Sq}, \mathrm{V}$ & Positive & pT4N2M0 \\
\hline 31 & $45 / 39$ & $9 / 13$ & $7 / 2$ & $61 / 54$ & $\mathrm{Sq}, \mathrm{V}$ & Positive & pT3N1M0 \\
\hline 32 & $13 / 11$ & $12 / 13$ & $5 / 2$ & $30 / 26$ & ${ }^{a}$ Negative, III & Positive & pT2NOM0 \\
\hline 33 & $31 / 26$ & $23 / 15$ & $3 / 5$ & $56 / 46$ & $\mathrm{Sq}, \mathrm{V}$ & Positive & pT3N1M0 \\
\hline 34 & $48 / 38$ & $24 / 19$ & $11 / 12$ & $83 / 69$ & $\mathrm{Sq}, \mathrm{V}$ & Positive & pT2NOMO \\
\hline 35 & $20 / 21$ & $13 / 16$ & $9 / 7$ & $42 / 44$ & $\mathrm{Sq}, \mathrm{V}$ & Positive & pT2N1M0 \\
\hline 36 & $19 / 21$ & $8 / 5$ & $12 / 12$ & $39 / 38$ & $\mathrm{Sq}, \mathrm{V}$ & Positive & pT2NOM0 \\
\hline 37 & $17 / 17$ & $20 / 15$ & $10 / 10$ & $47 / 42$ & $\mathrm{Sq}, \mathrm{V}$ & Positive & pT3N1M0 \\
\hline 38 & $21 / 22$ & $9 / 6$ & $3 / 1$ & $33 / 29$ & ${ }^{a}$ Negative, III & Positive & pT1NOM0 \\
\hline 39 & $25 / 20$ & $19 / 16$ & $8 / 7$ & $52 / 43$ & $\mathrm{Sq}, \mathrm{V}$ & Positive & pT2N1M0 \\
\hline 40 & $13 / 11$ & $6 / 7$ & $5 / 8$ & $24 / 26$ & ${ }^{a}$ Negative, II & Positive & pT1NOM0 \\
\hline 41 & $20 / 17$ & $10 / 9$ & $4 / 2$ & $34 / 28$ & $\mathrm{Sq}, \mathrm{IV}$ & Positive & pT2NOM0 \\
\hline 42 & $15 / 12$ & $9 / 11$ & $6 / 7$ & $30 / 30$ & Sq, IV & Positive & pT2N1M0 \\
\hline 43 & $32 / 23$ & $11 / 6$ & $7 / 7$ & $50 / 36$ & $\mathrm{Sq}, \mathrm{V}$ & Positive & pT2NOMO \\
\hline 44 & $51 / 47$ & $16 / 12$ & $9 / 9$ & $76 / 68$ & $\mathrm{Sq}, \mathrm{V}$ & Positive & pT2NOM0 \\
\hline 45 & $29 / 20$ & $14 / 20$ & $15 / 21$ & $58 / 61$ & Sq, V & Positive & pT3N2M0 \\
\hline 46 & $44 / 38$ & $19 / 13$ & $10 / 7$ & $73 / 58$ & $\mathrm{Sq}, \mathrm{V}$ & Positive & pT4N3M0 \\
\hline 47 & $20 / 17$ & $23 / 22$ & $11 / 9$ & $54 / 48$ & $\mathrm{Sq}, \mathrm{V}$ & Positive & pT2NOM0 \\
\hline 48 & $49 / 41$ & $20 / 15$ & $13 / 6$ & $82 / 62$ & $\mathrm{Sq}, \mathrm{V}$ & Positive & pT2N1M0 \\
\hline 49 & $29 / 25$ & $19 / 15$ & $12 / 12$ & $60 / 52$ & $\mathrm{Sq}, \mathrm{V}$ & Positive & pT3NOMO \\
\hline 50 & $38 / 32$ & $25 / 19$ & $13 / 5$ & $76 / 56$ & Ad, V & Positive & pT3N2M0 \\
\hline
\end{tabular}

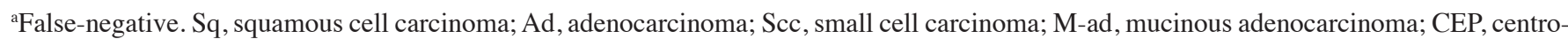
meric enumeration probe ; II-V, grade; FISH, fluorescence in situ hybridization. 
pathological staging confirmed stage IA in 2 cases, and stage IIA in 1 case, suggesting that FISH is capable of detecting the relevant chromosomal mutations in EC earlier. Therefore, FISH has its own clinical detection value for the early diagnosis of EC, and our findings have been supported by other studies $(9,12,18)$. FISH may provide objective information on malignant cells, particularly in tissues with moderate or severe dysplasia. Therefore, we recommend FISH as an ancillary test in cases with moderate or severe dysplasia in order to avoid the misdiagnosis of EC $(19,20)$.

The FISH results showed that the copy numbers of centromeres in chromosome 3 were significantly higher than those of chromosome $17(\mathrm{P}=0.0001)$. The results may be associated with the lifestyle of the Kazakh ethnic group, such as longterm excessive consumption of smoked meat, fermented foods, alcohol and tobacco, spicy foods, and lack of vegetables and foods rich in vitamins $(1,20)$. In the future, the most sensitive probes should be selected to improve the early diagnosis of EC using molecular pathological techniques $(9,10,21)$.

In this study, centromeres of chromosome 3 and 17 copy numbers and degree of aneuploidy were suggested to be correlated with the grade of tumor malignancy. These observations should be proven in future studies.

In conclusion, FISH technology is more sensitive than conventional pathology using biopsy specimens. Therefore, using an ancillary FISH test during the pathological diagnosis of cases with moderate or severe dysplasia may effectively improve the early diagnosis of EC. In addition, the centromeres of the chromosome 3 probe may be the most sensitive probe diagnostically in Kazakh patients with EC.

\section{Acknowledgements}

This study was supported by a grant from the Chinese postdoctoral fund of Xinjiang Medical University (20080-3014) and the Xinjiang Uygur Autonomous Region key disciplines Fund. Thanks are extended to the Department of Hematology, First Affiliated Hospital of Xinjiang Medical University for the technical support. We give thanks to Professor J. Patrick Barron, Professor and Chairman, Department of International Medical Communications, Tokyo Medical University for his review of this manuscript.

\section{References}

1. Zhang YM: Distribution of esophageal cancer in the Xinjiang. XMU Med 11: 139-145, 1988.

2. Enzinger PC and Mayer RJ: Esophageal cancer. N Engl J Med 349: 2241-2252, 2003

3. Krasna MJ: Multimodality therapy for esophageal cancer. Oncology 24: 1134-1138, 2010
4. Odze RD: Barrett esophagus: histology and pathology for the clinician. Nat Rev Gastroenterol Hepatol 6: 478-490, 2009.

5. Yerian L: Histology of metaplasia and dysplasia in Barrett's esophagus. Surg Oncol Clin N Am 18: 411-422, 2009.

6. Duesberg P, Li R, Rasnick D, Rausch C, Willer A, Kraemer A, Yerganian G and Hehlmann R: Aneuploidy precedes and segregates with chemical carcinogenesis. Cancer Genet Cytogenet 119: 83-93, 2000.

7. Rajagopalan $\mathrm{H}$ and Lengauer $\mathrm{C}$ : Aneuploidy and cancer. Nature 432: 338-341, 2004.

8. Halling $\mathrm{KC}$ and Kipp BR: Fluorescence in situ hybridization in diagnostic cytology. Hum Pathol 38: 1137-1144, 2007.

9. Fritcher EG, Brankley SM, Kipp BR, Voss JS, Campion MB, Morrison LE, Legator MS, Lutzke LS, Wang KK, Sebo TJ and Halling KC: A comparison of conventional cytology, DNA ploidy analysis, and fluorescence in situ hybridization for the detection of dysplasia and adenocarcinoma in patients with Barrett's esophagus. Hum Pathol 39: 1128-1135, 2008.

10. Idiris A, Madiniyet N, Xie HZ, Hadeti B, Zhang HY, Zhang Z, Ilyar S, Zhang CM, Zhang LW and Wen H: Genetic diagnosis of patients with esophageal cancer using FISH. Oncol Lett 1: 809-814, 2010.

11. Murphy CG and Fornier M: HER2-positive breast cancer: beyond Trastuzumab. Oncology 24: 410-415, 2010.

12. Han QY, Shun H, Yu PW, Xiao CW, Ya LH and Xin X: Application of multicolor fluorescence in situ hybridization to early diagnosis of esophageal squamous cell carcinoma. Chin J Can 27: 1137-1143, 2008.

13. Yang Y, Fruehauf J, Xiang S and Li CJ: Genomic instability in precancerous lesions before inactivation of tumor suppressors p53 and APC in patients. Cell Cycle 13: 1443-1447, 2006.

14. Nakamura H, Aute I, Kawasaki N, Taguchi M, Ohira T and Kato H: Quantitative detection of lung cancer cells by fluorescence in situ hybridization: comparison with conventional cytology. Chest 128: 906-911, 2005.

15. Dey P: Aneuploidy and malignancy: an unsolved equation. J Clin Pathol 57: 1245-1249, 2004.

16. Albertson DG, Collins C, McCormick F and Gray JW: Chromosome aberrations in solid tumors. Nat Genet 34: 369-76, 2003.

17. Falk GW, Skacel M, Gramlich TL, Casey G, Goldblum JR and Tubbs RR: Fluorescence in site hybridization of cytologic specimens from Barrett's esophagus: a pilot feasibility study. Gastrointest Endosc 60: 280-284, 2004.

18. Fahmy M, Skacel M, Gramlich TL, Brainard JA, Rice TW, Goldblum JR, Connor JT, Casey G, Legator MS, Tubbs RR and Falk GW: Chromosomal gains and genomic loss of p53 and p16 genes in Barrett's esophagus detected by fluorescence in situ hybridization of cytology specimens. Mod Pathol 17: 588-596, 2004.

19. Fiegl M, Massoner A, Haun M, Sturm W, Kaufmann H, Hack R, Krugmann J, Fritzer-Szekeres M, Grünewald K and Gastl G: Sensitive detection of tumour cells in effusions by combining cytology and fluorescence in situ hybridisation (FISH). Br J Cancer 91: 558-563, 2004.

20. Bahmanyar S and Ye W: Dietary patterns and risk of squamous-cell carcinoma and adenocarcinoma of the esophagus and adenocarcinoma of the gastric cardia: a population based case-control study in Sweden. Nutr Cancer 54: 171-178, 2006.

21. Delektorskaya VV, Chemeris GY, Zavalishina LE, Ryazantseva AA, Grigorchuk AY, Kononets PV and Davydov MI: Squamous cell carcinoma of the esophagus: evaluation of the status of epidermal growth factor receptors (EGFR and HER-2) by immunohistochemistry and in situ hybridization. Bull Exp Biol Med 149: 615-620, 2010. 